УДК 32

Яхшиян Олег Юрьевич

канд. ист. наук, ФГБОУ ВО «Государственный университет управления», г. Москва, Российская Федерация

ORCID: 0000-0003-0097-5193

e-mail:yakhshiyan@mail.ru

\section{Волох Владимир}

\section{Александрович}

д-р полит. наук, ФГБОУ ВО «Государственный университет управления», г. Москва, Российская Федерация ORCID: 0000-0003-1292-7631

e-mail:v.volokh@yandex.ru

\section{ПОПРАВКИ В КОНСТИТУЦИЮ РОССИЙСКОЙ ФЕДЕРАЦИИ КАК ОСНОВА ПОЛИТИКИ ИДЕНТИЧНОСТИ В РОССИЙСКОЙ ФЕДЕРАЦИИ}

\begin{abstract}
Аннотация. Статья посвящена рассмотрению поправок в Конституциюю Российской Федерации, одобренных в ходе голосования 1 июля 2020 г., которые задают основные параметры политики идентичности в нашей стране. Особое внимание уделено реакиии общественных деятелей, экспертов и представителей руководства республик в составе Российской Федерации. В ходе обсуждения поправок обнаружился мощный общзественный запрос на прояснение и фиксачию в виде конституичионых положений основных содержательных культурно-иивилизачионных параметров российской идентичности. Принятие поправок продемонстрировало широкое общественное согласие относительно конституционно задаваемых параметров российской национальной идентичности. Обсуждение показало неоднозначное отношение этнических активистов в республиках к задаваемым параметрам политики идентичности. А руководители ряда республик обозначили свое особое мнение, отразивщее определенное напряжение по поводу включения в статью о государственном языке понятия «государствообразующий народ».
\end{abstract}

Ключевые слова: государственный язык, государствообразующий народ, конституиия, политика идентичности, поправки, российская национальная идентичность, русский народ, этнокультурное многообразие, языковое многообразие.

Для цитирования: Яхшиян О.Ю., Волох В.А. Поправки в Конституцию Российской Федерации как основа политики идентичности в Российской Федерации//Вестник университета. 2020. № 11. С. 217-224.

\section{AMENDMENTS TO THE CONSTITUTION OF THE RUSSIAN FEDERATION AS THE BASIS OF IDENTITY POLICY IN THE RUSSIAN FEDERATION}

\begin{abstract}
The article is devoted to the consideration of amendments to the Constitution of Russia approved during the vote on July 1, 2020, which set the main parameters of identity policy in our country. Special attention is paid to the reaction of public figures, experts and representatives of the leadership of the republics within the Russian Federation. During the discussion of the amendments, there was a strong public demand to clarify and fix in the form of constitutional provisions the main content of cultural and civilizational parameters of the Russian identity. The adoption of the amendments demonstrated broad public agreement on the constitutionally defined parameters of Russian national identity. The discussion showed an ambiguous attitude of ethnic activists in the republics to the set parameters of identity policy. And the leaders of a number of republics expressed their dissenting opinion, which reflected a certain tension over the inclusion of the concept of "state-forming people"in the article on the state language.
\end{abstract}

Keywords: amendments, constitution, ethno-cultural diversity, identity policy, linguistic diversity, Russian national identity, Russian people, state-forming people, state language.

For citation: Yakhshiyan O.Yu., Vladimir V.A. (2020) Amendments to the Constitution of the Russian Federation as the basis of identity policy in the Russian Federation. Vestnik universiteta. I. 11, pp. 217 224. DOI: $10.26425 / 1816-4277-2020-11-217-224$

Политика идентичности - это деятельность государства и других политических акторов по формированию и воспроизводству общих ценностных и культурных оснований принадлежности к единому гражданско-политическому сообществу (нации), общих ориентиров развития и представлений о стране и ее прошлом. В таком понимании политика идентичности совокупно реализуется средствами образовательной, культурной, языковой,

Благодарности. Исследование выполнено при финансовой поддержке РФФИ и ЭИСИ в рамках научного проекта № 20-011-31303.

Acknowledgements. The research was supported by the RFBR and EISR under the scientific project No. 20-011-31303.

(C) Яхшиян О.Ю., Волох В.А., 2020. Статья доступна по лицензии Creative Commons «Attribution» («Атрибуция») 4.0. всемирная (http://creativecommons.org/licenses/by/4.0/).

The Author(s), 2020. This is an open access article under the CC BY 4.0 license (http://creativecommons.org/licenses/by/4.0/). 
информационной, символической политики (политики исторической памяти) и др. В Российской Федерации вопросы политики идентичности находятся в сфере постоянного приоритетного интереса и внимания Президента страны. В. В. Путин в своих публичных выступлениях и статьях вновь и вновь обращается к этой проблематике, последовательно проясняя и уточняя собственное ее понимание и для органов государственной власти всех уровней, и для общества. Проблематика национальной идентичности, особенно в аспектах политики памяти и языка, в возрастающей мере находит отражение в законодательстве Российской Федерации. В корпусе действующих документов стратегического планирования эта проблематика в наибольшей степени изложена в Стратегии государственной национальной политики Российской Федерации на период до 2025 г. [2].

Когда в январе 2020 г. президент России инициировал внесение изменений в действующую Конституцию, общество активно включилось в процесс подготовки и обсуждения предлагаемых поправок. В ходе этой работы среди прочего выявился серьезный общественный запрос на прояснение и фиксацию в виде конституционных положений основных содержательных культурно-цивилизационных параметров российской идентичности. Дискурс по принципиальным проблемам политики идентичности в нашей стране получил даже несколько неожиданно мощный импульс.

Большой резонанс вызвало предложение зафиксировать в Конституции государствообразующую роль русского народа. Отстаивая это предложение, К. Ф. Затулин особо оговорил, что русский народ в России, как и каждый русский человек в отдельности, не вправе претендовать на какие-либо льготы и привилегии по этническому признаку. Статья 19 главы 2 Конституции гласит, что государство гарантирует равенство прав и свобод человека и гражданина независимо от пола, расы, национальности, языка, происхождения и других обстоятельств. Конституция запрещает любые формы ограничения прав граждан по признакам социальной, расовой, национальной, языковой или религиозной принадлежности. Но именно будучи многонациональным, Российское государство не может не артикулировать свое позиционирование по отношению к русском народу и русской культуре. Иначе оно провоцирует утверждения вроде того, что «русский народ не имеет собственного государства», а Российская Федерация «не рассматривает себя и не является на деле государством русского народа» [25, с. 13]. Иначе, как отметил К. Ф. Затулин, русские поневоле будут искать своей самоидентификации, как сейчас, в уставах отдельных краев и областей. Иначе казаки, поморы и другие группы внутри русского народа будут идти по пути обособления, чтобы обрести право на признание отдельным народом, территорию и др. Автор справедливо пишет о том, что в России комплементарность по отношению к русскому народу - норма и обязательное условие межэтнических коммуникаций [10]. Отрицать «русскость» России также недопустимо, как и ее многонациональность.

На встрече с рабочей группой по подготовке предложений о внесении поправок в Конституцию 26 февраля 2020 г. В. В. Путин поддержал предложенную М. Б. Пиотровским формулировку статьи 68, которая в итоговом варианте гласит: «Государственным языком Российской Федерации на всей ее территории является русский язык как язык государствообразующего народа, входящего в многонациональный союз равноправных народов Российской Федерации» [1, с. 27]. Государствообразующий статус русского народа прописывается в связи со статусом русского языка как государственного на всей территории России. Однако сомнения и тревоги в связи с формулировкой о государствообразующем народе не утихли. Член президентского Совета по межнациональным отношениям Л. М. Дробижева прогнозирует трудности при интерпретации предложенной формулировки: «Скажем, да, русские будут считать, что, раз русский - язык государствообразующего народа, значит, это мы государствообразующий народ. Тогда выходит, что кто-то таковым не является? Люди, являющиеся по национальности не русскими, будут спрашивать: «А как же мы не граждане? Мы что, не голосуем на выборах, в том числе за Конституцию? Мы не живем по законам нашего государства? Не создаем ценности?» [9] Она предположила, что отдельные радикально настроенные элементы могут использовать эту формулировку для разжигания межнациональной розни, трактуя ее в смысле утверждения превосходства русской нации. С ней солидарен старший научный сотрудник Центра изучения Кавказа МГИМО А. А. Ярлыкапов, который высказал опасения, что рост радикализма вполне возможен на этом фоне. По его мнению, люди будут обособляться в республиках Российской Федерации и вместо консолидации российского народа получится фрагментация [16]. Муфтий Татарстана К. И. Самигуллин высказал сомнение в целесообразности такой формулировки. По его словам, все мы россияне, и все мы внесли вклад в образование этого государства, в сохранение государственных границ и духовного суверенитета 
России, в формирование многоликого общероссийского менталитета и в развитие мощного социально-экономического пространства. А Верховный муфтий России Т. С. Таджуддин не увидел в предложенной формулировке выпячивания русского народа и счел ее вполне приемлемой [19]. Руководитель общественной организации «Аух» (Республика Дагестан) предположил, что создается риск введения подобного статуса для титульной национальности в республиках [16]. Один из руководителей Всемирного Русского народного собора К. В. Малофеев обратил внимание на конструкцию, содержащуюся в действующей Конституции Республики Татарстан: «Настоящая Конституция, выражая волю многонационального народа Республики Татарстан и татарского народа...» [17]. Тем не менее Совет Всемирного форума татарской молодежи заявил, что понятие «государствообразующий народ» автоматически предполагает деление народов на различные «сорта», и представители нерусских национальностей провозглашаются народами «второго сорта». Таким образом в Конституции будет оформлена иерархия народов [4]. Один из башкирских общественных деятелей соглашается, что такое нововведение грозит неблагоприятными последствиями. Во-первых, это может вызвать ответный рост антирусских настроений внутри страны. Во-вторых, другие народы будут чувствовать себя дискомфортно, поскольку, в отличие от русских, они не будут упомянуты в Основном законе [23]. «Получается, все народы, кроме русского, стали вдруг не государствообразующими. А какими тогда? Как тогда определить другие народы? Если русский народ государствообразующий, а татары тогда какой народ? Просто проживающий на территории государствообразующего народа? Или государствообразующий в своих республиках? Тогда это получается укрепление сепаратизма и центробежных тенденций», - рассуждает публицист М. Л. Шевченко [24]. Конгресс Саха в своем обращении к Президенту и парламенту России заявил: «Введение в Основной Закон крупнейшего многонационального государства мира, образовавшегося на протяжении длительного отрезка исторического времени как уникальный сплав народов самых разных языков, традиций, культур и вероисповеданий, понятия «государствообразующего народа», подразделяющего народы России на один главенствующий и другие второстепенные, является опаснейшим и безответственным социальным экспериментом» [15]. Политолог А. Б. Шатилов, на наш взгляд, верно определил важнейший политический смысл данной поправки: она позиционирует русский язык как важнейшую составляющую российской идентичности [21]. Сопредседатель Межнационального совета общественных организаций Карачаево-Черкесии Р. Х. Хабов высоко охарактеризовал роль русского языка в развитии культуры народов Северного Кавказа: благодаря развитию русского языка они смогли познакомиться с произведениями великих русских классиков, которые давно стали неотъемлемой частью мирового культурного наследия. В то же время при помощи русского языка далеко за пределами региона стали известны и имена национальных авторов Северного Кавказа, а их произведения вошли в сокровищницу отечественной литературы [20]. Председатель Совета отцов Республики Тыва Хонук-оол Монгуш отметил, что языки малых народов развиваются как за счет сохранения национальной культуры, так и за счет обогащения, например, благодаря переводам на родной язык произведений великих классиков русской литературы, общих научных проектов [22].

Председатель Государственного Собрания - Курултая Республики Башкортостан К. Б. Толкачев назвал весьма странным предложение закрепить в Конституции особую роль русского народа как государствообразующего. По его мнению, такое предложение противоречит принципу многонациональности, а также «исторической логике развития страны» [13]. Президент Республики Татарстан Р. Н. Минниханов высказался несколько противоречиво. сама идея о русском народе и языке не вызывает опасений, однако формулировка требует доработки. Но потом разъяснил, что это поначалу формулировка казалась ему «вызывающей», но если внимательно прочитать статью, то все вопросы снимаются: «Русский язык для нас всех - государственный язык. Владелец русского языка - русский народ. Здесь никто не спорит» [14]. Председатель Государственного Совета Республики Татарстан входил в состав рабочей группы по подготовке поправок и на встрече с В. В. Путиным высказал обеспокоенность относительно возможности изучения языков народов республики. В ответ Президент обратил внимание, что впервые в Конституцию вносится положение, согласно которому государство будет обязано защищать языковое многообразие народов России [5].

Показательно, что вносимые в Основной закон поправки «в одном пакете» гарантируют и статус русского языка как государственного на всей территории страны, и право республик устанавливать свои государственные языки, и право всех народов на сохранение родного языка, создание условий для его изучения и развития. Тем самым изменения в Конституцию закрепляют одну из важнейших установок российской политики 
идентичности: обязательное русскоязычие при недопущении языковой ассимиляции и специальных усилиях государства по сохранению языков народов России. Глава Республики Тыва Шолбан Кара-Оол 3 марта 2020 г. на своей странице в социальной сети «ВКонтакте» разместил пост, в котором отметил, что сохранение языка - это глубинная основа развития каждого народа: «Конституционную защиту русского языка считаю верной. Для малых народов России он всегда был крепкой опорой жизнестойкости» [11]. Предлагаемые поправки закрепляют традиции и историю народа, дают право национальным республикам устанавливать свой язык, как государственный. Такое языковое многообразие и должно быть отражено в Конституции Российской Федерации. Глава Республики Крым С. В. Аксенов заявил, что поправки к Основному закону в полной мере отражают как объединяющую роль русского языка, так и интересы всех граждан нашей многонациональной страны. Он напомнил, что в Конституции Республики Крым закреплен государственный статус трех языков: русского, украинского и крымско-татарского [3]. Председатель Госсовета-Хасэ Адыгеи В. И. Нарожный заявил: «Сегодня в нашей стране есть все гарантии для сохранения и изучения языков. Очень важно, что эта норма будет отражена в Конституции Российской Федерации. Поправки дают все основания быть уверенным в том, что языки народов, проживающих в нашей стране, получат дальнейшее свое развитие. Эти вопросы имеют для нашей страны важнейшее значение для гармонизации межнациональных отношений, обеспечения гражданского единства, укрепления государственного суверенитета и целостности России» [7].

Некоторые эксперты предложили такое толкование, согласно которой все мы, объединенные русским языком, становимся государствообразующим народом. Ведь в формулировке статьи русский народ прямо не называется государствообразующим. При таком подходе все народы России - государствообразующие [12]. Однако Конституционный суд в своем заключении от 16 марта 2020 г. указал, что это положение основано на объективном признании роли именно русского народа в образовании российской государственности, продолжателем которой является Российская Федерация. В заключении суда подчеркивается, что это положение не умаляет достоинства других народов и не может рассматриваться как несовместимое с положениями Конституции о многонациональном народе Российской Федерации, о равенстве прав и свобод человека и гражданина независимо от национальности, о равноправии и самоопределении народов [1]. Заключение Конституционного суда снимает все сомнения, что под государствообразующим понимается именно русский народ и уточняет значение понятия, вызвавшего бурные дискуссии. Обращаясь к также вносимому в Конституцию положению об исторически сложившемся государственном единстве, Конституционный суд связывает именно с русским народом непрерывность (континуум) отечественной государственности во всех ее сменявших друг друга конкретно-политических ипостасях. Действительно, именно судьба русского народа связывает в единое и продолжающееся во времени историческое единство Руси домонгольской, Московского царства, Российской империи, Советского Союза и Российской Федерации.

Поправки включают статью 67.1, положения которой закладывают принципиальные основания российской политики идентичности. Речь идет о правопреемстве в отношении СССР и, более широко - об исторической преемственности в развитии Российского государства. В. В. Путин прокомментировал это положение следующим образом: «Россия развивалась исторически и во все периоды - и в Древней Руси, и в период Московского царства, и в период Советского Союза, и сейчас, в наше время, - это одна страна» [8]. Национальная идентичность формируется в контексте дискурсов и нарративов об истории страны, определяющих общее видение прошлого и будущего. Важнейшей составной частью политики идентичности выступает политика памяти. Представление о том, откуда мы, кто наши предки, образ «эстафеты поколений», ценностное восприятие прошлого, «священные камни» - все это определяет историческое самосознание. На встрече с президентом 13 февраля 2020 г. член рабочей группы по подготовке поправок А. К. Пушков, говоря о нескончаемых попытках ряда стран переписать историю Второй мировой войны и представить в превратном свете роль СССР, предложил закрепить в Конституции статус России как державы-победительницы [6]. В итоге в Конституцию было решено внести следующее положение, в существенной степени обусловливающее политику идентичности в России: «Российская Федерация чтит память защитников Отечества, обеспечивает защиту исторической памяти. Умаление значения подвига народа при защите Отечества не допускается» [1, с. 27].

В целом изменения, одобренные в ходе общероссийского голосования 1 июля 2020 г., содержат принципиальные конституционные ориентиры для политики идентичности в нашей стране. Они фиксируют ценности и представления, во многом безусловные для россиян, определяющие общероссийскую культурную 
идентичность, само понятие которой включено в текст Конституции. Это ценность независимости и суверенитета, территориальной целостности России. Это представление о преемственности в развитии отечественной государственности, о недопустимости разрыва «связи времен» и тотального очернения той или иной эпохи в истории нашей страны. Это идея исторической ответственности ныне живущего и последующих поколений россиян перед памятью предков. Указание на идеалы и веру в Бога фиксирует приверженность нравственным нормам и идеалам, свойственным традиционным религиям народов России. Это ценность исторической правды, в особенности - правды о решающей роли советского народа в разгроме нацизма. Это ценность традиционной семьи, материнства, отцовства и детства. По смыслу конституционных поправок известный минимум «русскости», в смысле культурно-цивилизационном, а не этническом, рассматривается как необходимый компонент российской национальной идентичности, как та самая русская культурная доминанта, присущая всем народам России и обеспечивающая общность языка, высокой культуры и истории. Русская культурная доминанта не требует от всех, кто ее принимает, считать себя русским, а русский язык - родным, но обязательно предполагает чувство исторической общности судеб народов России и русского народа, восприятие российской государственности и высокой русской культуры как общей и своей для всех народов страны. При этом обязательным конституционным условием политики укрепления российской идентичности определяется защита культурной самобытности всех народов России, сохранение этнокультурного и языкового многообразия.

Итоги голосования 1 июля 2020 г., как и данные многочисленных социологических опросов, убедительно продемонстрировали широкое общественное согласие по конституционно зафиксированным параметрам российской национальной идентичности. Голосуя на избирательном участке, Председатель Парламента Чеченской Республики М. Х. Даудов заявил, что главное, на что направлены изменения в Конституцию, - сохранение конфессиональных, исторических и культурных составляющих многонационального российского народа [18]. До этого, 12 марта 2020 г. законодательные собрания субъектов Российской Федерации, в том числе и парламенты республик, одобрили принятые ранее Государственной Думой и Советом Федерации поправки. Таким образом, руководство и элиты российских республик продемонстрировали свое согласие с предложенными конституционными подходами к политике идентичности в нашей стране. Это само по себе является серьезным политическим достижением кампании по внесению изменений в российскую Конституцию.

\section{Библиографический список}

1. Конституция Российской Федерации (принята всенародным голосованием 12.12 .1993 с изменениями, одобренными в ходе общероссийского голосования 01.07.2020) // СПС «КонсультантПлюс» [Электронный русурс]. - Режим доступа: http://www.consultant.ru/document/cons_doc_LAW_28399/(дата обращения: 28.09.2020).

2. Указ Президента Российской Федерации «О внесении изменений в Стратегию государственной национальной политики Российской Федерации на период до 2025 года, утвержденную Указом Президента Российской Федерации от 19.12.2012 № 1666 // Официальный сайт Президента Российской Федерации [Электронный русурс]. - Режим доступа: http://kremlin. ru/acts/news/59348 (дата обращения: 28.09.2020).

3. Аксёнов: Русский язык - одно из главных сокровищ нашей цивилизации // Крымская правда [Электронный русурс]. Режим доступа: https://c-pravda.ru/news/2020-06-06/aksjonov-russkijj-yazyk---odno-iz-glavnykh-sokrovishh-nashejj-civilizacii (дата обращения: 28.09.2020).

4. Антонов, К., Тяжлов, И. Государствообразумливающий народ. Татарстанские общественники считают дискриминационной поправку о русском языке // Коммерсантъ [Электронный русурс]. - Режим доступа: https://www.kommersant.ru/doc/4283282?utm_ source=yxnews\&utm_medium=desktop\&utm_referrer=https\%3A\%2F\%2Fyandex.ru\%2Fnews (дата обращения: 01.10.2020).

5. Верховный муфтий поддержал поправку в Конституцию о народе // РИА Новости [Электронный русурс]. - Режим доступа: https://ria.ru/20200303/1568116704.html (дата обращения: 28.09.2020)

6. Владимир Нарожный прокомментировал поправки по сохранению и развитию языков // Аргументы и Факты - Адыгея [Электронный русурс]. - Режим доступа: https://adigea.aif.ru/society/details/vladimir_narozhnyy_prokommentiroval_ popravki_po_sohraneniyu_i_razvitiyu_yazykov (дата обращения: 28.09.2020).

7. Встреча с рабочей группой по подготовке предложений о внесении поправок в Конституцию 13 февряля 2020 г. // Официальный сайт Президента Российской Федерации [Электронный русурс]. - Режим доступа: http://www.kremlin.ru/events/ president/news/62776 (дата обращения: 28.09.2020). 
8. Встреча с рабочей группой по подготовке предложений о внесении поправок в Конституцию 26 февряля 2020 г. // Официальный сайт Президента Российской Федерации [Электронный русурс]. - Режим доступа: http://www.kremlin.ru/events/ president/news/62862 (дата обращения: 28.09.2020).

9. Дробижева Леокадия: «Да, русские будут считать: мы государствообразующий народ» // Бизнес Online [Электронный pycypc]. - Режим доступа: https://www.business-gazeta.ru/article/460104 (дата обращения: 28.09.2020).

10. Затулин К. Пустите русских в Конституцию. Без русских России не может быть // Московский Комсомолец [Электронный русурс]. - Режим доступа: https://www.mk.ru/politics/2020/02/12/pustite-russkikh-v-konstituciyu.html (дата обращения: 28.09.2020).

11. «Защиту русского языка считаю верной» - глава Тувы об инициативе президента // ИA REGNUM [Электронный русурс]. - Режим доступа: https://regnum.ru/news/polit/2875452.html (дата обращения: 28.09.2020).

12. «Иногда лучше внимательнее прочитать»: Активисты пытаются стравить народы России, забыв об истине в Конституции? // Царьград [Электронный русурс]. - Режим доступа: https://yandex.ru/turbo/tsargrad.tv/s/news/inogda-luchshevnimatelnej-prochitat-aktivisty-pytajutsja-stravit-narody-rossii-zabyv-istine-v-konstitucii_242254 (дата обращения: 28.09.2020).

13. Казанцев, В. Спикер парламента Башкирии выступил против «особой роли русского народа» в Конституции // Комсомольская Правда [Электронный русурс]. - Режим доступа: https://www.ufa.kp.ru/online/news/3747399/ (дата обращения: 28.09.2020).

14. Калинина, Н. Глава Татарстана предложил изменить поправку к Конституции о русском языке // УРА.РУ [Электронный pycypc]. - Режим доступа: https://ura.news/news/1052421771 (дата обращения: 28.09.2020).

15. Конгресс Саха обратился к Владимиру Путину с призывом не вводить в Конституцию РФ понятия «государствообразующий народ» // Вести Якутии [Электронный русурс]. - Режим доступа: https://yandex.ru/turbo/vesti14.ru/s/2020/03/06/ kongress-saha-obratilsya-k-vladimiru-putinu-s-prizyvom-ne-vvodit-v-konstitutsiyu-rf-ponyatiya-gosudarstvoobrazuyushhijnarod/ (дата обращения: 28.09.2020).

16. Краснов, О. Поправка о государствообразующем народе поставила под вопрос принцип федерализма // Кавказский Узел [Электронный русурс]. - Режим доступа: https://www.kavkaz-uzel.eu/articles/346997/ (дата обращения: 28.09.2020).

17. Ломакина, О. Малофеев объяснил исторический контекст понятия «государствообразующий народ» // 360 [Электронный русурс]. - Режим доступа: https://360tv.ru/news/obschestvo/malofeev-objasnil-istoricheskij-kontekst-ponjatijagosudarstvoobrazujuschij-narod/ (дата обращения: 28.09.2020).

18. Магомед Даудов: Поправки в Конституцию направлены на сохранение конфессиональных, исторических и культурных составляющих многонационального российского народа // БезФормата [Электронный русурс]. - Режим доступа: https:// yakutsk.bezformata.com/listnews/magomed-daudov-popravki-v-konstitutciyu/85173988/ (дата обращения: 28.09.2020).

19. Муфтий Татарстана выступил против поправки в Конституцию о народе // РБК [Электронный русурс]. - Режим доступа: www.rbc.ru/politics/03/03/2020/5e5e63ce9a79472d4d8e6447 (дата обращения: 28.09.2020).

20. «Он помогает народам России общаться между собой»: В Карачаево-Черкесии поддержали поправки в Конституцию о русском языке // Царьград [Электронный русурс]. - Режим доступа: https://yandex.ru/turbo/tsargrad.tv/s/news/ on-pomogaet-narodam-rossii-obshhatsja-mezhdu-soboj-v-karachaevo-cherkessii-podderzhali-popravki-v-konstituciju-o-russkomjazyke_241638 (дата обращения: 28.09.2020).

21. Полубота, А. Эксперты рассказали, к чему приведет появление понятия «русские» в Конституции РФ // Федеральное агентство новостей [Электронный русурс]. - Режим доступа: https://riafan.ru/1254956-eksperty-rasskazali-k-chemu-privedetpoyavlenie-ponyatiya-russkie-v-konstitucii-rf (дата обращения: 28.09.2020).

22. Председатель Совета Отцов Тувы поддержал президентские поправки в Конституцию о языках // Тува-онлайн [Электронный русурс]. - Режим доступа: https://www.tuvaonline.ru/2020/03/04/predsedatel-soveta-otcov-tuvy-podderzhal-prezidentskiepopravki-v-konstituciyu-o-yazykah.html (дата обращения: 28.09.2020).

23. Рахматуллин, Т. Кому на руку «русская статья» в Конституции? // Реальное время [Электронный русурс]. - Режим доступа: https://realnoevremya.ru/articles/167691-komu-budet-na-ruku-russkaya-statya-konstitucii (дата обращения: 28.09.2020).

24. Федорова, Е. Шевченко Максим: «Если русский народ государствообразующий, то татары какой?» // Московский Комсомолец - Казань [Электронный русурс]. - Режим доступа: https://kazan.mk.ru/politics/2020/03/04/maksim-shevchenkoesli-russkiy-narod-gosudarstvoobrazuyushhiy-to-tatary-kakoy.html (дата обращения: 28.09.2020).

25. Холмогоров, Е. С. Русская проблема // Русский дом. - 2014. - № 1 [Электронный русурс]. - Режим доступа: http://www. russdom.ru/node/7400 (дата обращения: 28.09.2020). 


\section{References}

1. Konstitutsiya Rossiiskoi Federatsii (prinyata vsenarodnym golosovaniem $12.12 .1993 \mathrm{~s}$ izmeneniyami, odobrennymi v khode obshcherossiiskogo golosovaniya 01.07.2020) [Constitution of the Russian Federation (adopted by popular vote on December 12, 1993 and amended by a nationwide vote on July 01, 2020)]. SPS “ConsultantPlus". Available at: http://www.consultant. ru/document/cons_doc_LAW_28399/(accessed 28.09.2020).

2. Ukaz Prezidenta Rossiiskoi Federatsii “O vnesenii izmenenii v Strategiyu gosudarstvennoi natsional'noi politiki Rossiiskoi Federatsii na period do 2025 goda, utverzhdennuyu Ukazom Prezidenta Rossiiskoi Federatsii ot 19.12.2012 № 1666” [Decree of the President of the Russian Federation "On Amendments to the Strategy of State National Policy of the Russian Federation for the period until 2025, approved by Decree of the President of the Russian Federation of December 19, 2012 No. 1666]. Ofitsial'nyi sait Prezidenta Rossiiskoi Federatsii [Official website of the President of the Russian Federation]. Available at: http://kremlin. ru/acts/news/59348 (accessed 28.09.2020).

3. Aksenov: Russkii yazyk - odno iz glavnykh sokrovishch nashei tsivilizatsii [Aksyonov: The Russian language is one of the main treasures of our civilisation]. Krymskaya pravda. Available at: https://c-pravda.ru/news/2020-06-06/aksjonov-russkijj-yazyk--odno-iz-glavnykh-sokrovishh-nashejj-civilizacii (accessed 28.09.2020).

4. Antonov K., Tyazhlov, I. Gosudarstvoobrazumlivayushchii narod. Tatarstanskie obshchestvenniki schitayut diskriminatsionnoi popravku o russkom yazyke [The state brings people to reason. Tatarstan public figures consider the Russian language amendment discriminatory]. Kommersant. Available at: https://www.kommersant.ru/doc/4283282?utm_source=yxnews\&utm_medium=desktop\&utm_referrer=https\%3A\%2F\%2Fyandex.ru\%2Fnews (accessed 28.09.2020).

5. Verkhovnyi muftii podderzhal popravku v Konstitutsiyu o narode [The Supreme mufti supported the amendment to the Constitution on the people]. RIA Novosti. Available at: https://ria.ru/20200303/1568116704.html (accessed 28.09.2020)

6. Vladimir Narozhnyi prokommentiroval popravki po sokhraneniyu i razvitiyu yazykov [Vladimir Narozhny commented on the amendments on conservation and development of languages]. Argumenty i Fakty - Adygeya. Available at: https://adigea.aif.ru/ society/details/vladimir_narozhnyy_prokommentiroval_popravki_po_sohraneniyu_i_razvitiyu_yazykov (accessed 28.09.2020).

7. Vstrecha s rabochei gruppoi po podgotovke predlozhenii o vnesenii popravok v Konstitutsiyu 13 fevryalya 2020 g. [Meeting with the working group to prepare proposals for constitutional amendments on February 13, 2020]. Ofitsial'nyi sait Prezidenta Rossiiskoi Federatsii [Official website of the President of the Russian Federation]. Available at: http://www.kremlin.ru/events/ president/news/62776 (accessed 28.09.2020).

8. Vstrecha s rabochei gruppoi po podgotovke predlozhenii o vnesenii popravok v Konstitutsiyu 26 fevryalya 2020 g. [Meeting with the working group to prepare proposals for constitutional amendments on February 26, 2020]. Ofitsial'nyi sait Prezidenta Rossiiskoi Federatsii [Official website of the President of the Russian Federation]. Available at: http://www.kremlin.ru/events/ president/news/62862 (accessed 28.09.2020).

9. Drobizheva Leokadiya: "Da, russkie budut schitat': my gosudarstvoobrazuyushchii narod" [Drobizheva Leokadia: "Yes, Russians will count: we are the state-forming people”]. Biznes Online. Available at: https://www.business-gazeta.ru/article/460104 (accessed 28.09.2020).

10. Zatulin K. Pustite russkikh v Konstitutsiyu. Bez russkikh Rossii ne mozhet byt' [Let the Russians into the Constitution. Without Russians, there can be no Russia]. Moskovskii Komsomolets. Available at: https://www.mk.ru/politics/2020/02/12/pustite-russkikh-v-konstituciyu.html (accessed 28.09.2020).

11. "Zashchitu russkogo yazyka schitayu vernoi" - glava Tuvy ob initsiative prezidenta ["I consider the Protection of the Russian language to be true" - The Head of Tuva on the President's initiative]. IA REGNUM. Available at: https://regnum.ru/news/ polit/2875452.html (accessed 28.09.2020).

12. "Inogda luchshe vnimatel'nee prochitat": Aktivisty pytayutsya stravit' narody Rossii, zabyv ob istine v Konstitutsii? ["Sometimes it's better to read more carefully": Activists try to pit the peoples of Russia against each other, forgetting the truth in the Constitution?]. Tsar'grad. Available at: https://yandex.ru/turbo/tsargrad.tv/s/news/inogda-luchshe-vnimatelnej-prochitat-aktivisty-pytajutsja-stravit-narody-rossii-zabyv-istine-v-konstitucii_242254 (accessed 28.09.2020).

13. Kazantsev V. Spiker parlamenta Bashkirii vystupil protiv "osoboi roli russkogo naroda" v Konstitutsii [The speaker of the Bashkiria Parliament opposed the "special role of the Russian people" in the Constitution]. Komsomol'skaya Pravda. Available at: https://www.ufa.kp.ru/online/news/3747399/ (accessed 28.09.2020).

14. Kalinina, N. Glava Tatarstana predlozhil izmenit' popravku k Konstitutsii o russkom yazyke [Tatarstan President proposed to change the amendment to the Constitution on the Russian language]. URA.RU. Available at: https://ura.news/news/1052421771 (accessed 28.09.2020). 
15. Kongress Sakha obratilsya k Vladimiru Putinu s prizyvom ne vvodit'v Konstitutsiyu RF ponyatiya "gosudarstvoobrazuyushchii narod" [Congress Saha appealed to Vladimir Putin with an appeal not to enter into the Constitution of the Russian Federation the concept of "constituent peoples"]. Vesti Yakutii. Available at: https://yandex.ru/turbo/vesti14.ru/s/2020/03/06/kongress-saha-obratilsya-k-vladimiru-putinu-s-prizyvom-ne-vvodit-v-konstitutsiyu-rf-ponyatiya-gosudarstvoobrazuyushhij-narod/ (accessed 28.09.2020).

16. Krasnov O. Popravka o gosudarstvoobrazuyushchem narode postavila pod vopros printsip federalizma [The state-forming people amendment called into question the principle of federalism]. Kavkazskii Uzel. Available at: https://www.kavkaz-uzel.eu/ articles/346997/ (accessed 28.09.2020).

17. Lomakina O. Malofeev ob"yasnil istoricheskii kontekst ponyatiya "gosudarstvoobrazuyushchii narod" [Malofeev explained the historical context of the notion of a 'state-forming people']. 360. Available at: https://360tv.ru/news/obschestvo/malofeev-objasnil-istoricheskij-kontekst-ponjatija-gosudarstvoobrazujuschij-narod/ (accessed 28.09.2020).

18. Magomed Daudov: Popravki v Konstitutsiyu napravleny na sokhranenie konfessional'nykh, istoricheskikh i kul'turnykh sostavlyayushchikh mnogonatsional'nogo rossiiskogo naroda [Magomed Daudov: Constitutional amendments are aimed at preserving the confessional, historical and cultural components of the multinational Russian people]. BezFormata. Available at: https:/yakutsk.bezformata.com/listnews/magomed-daudov-popravki-v-konstitutciyu/85173988/ (accessed 28.09.2020).

19. Muftii Tatarstana vystupil protiv popravki v Konstitutsiyu o narode [The Mufti of Tatarstan opposed the amendment to the Constitution on the people]. RBK [RBC]. Available at: www.rbc.ru/politics/03/03/2020/5e5e63ce9a79472d4d8e6447 (accessed 28.09.2020).

20. "On pomogaet narodam Rossii obshchat'sya mezhdu soboi”: V Karachaevo-Cherkesii podderzhali popravki v Konstitutsiyu o russkom yazyke ["It helps the peoples of Russia communicate with each other": Karachay-Cherkessia supported amendments to the Constitution on the Russian language]. Tsar'grad. Available at: https://yandex.ru/turbo/tsargrad.tv/s/news/on-pomogaet-narodam-rossii-obshhatsja-mezhdu-soboj-v-karachaevo-cherkessii-podderzhali-popravki-v-konstituciju-o-russkom-jazyke_241638 (accessed 28.09.2020).

21. Polubota, A. Eksperty rasskazali, $\mathrm{k}$ chemu privedet poyavlenie ponyatiya "russkie" $\mathrm{v}$ Konstitutsii RF [Experts told what will lead to the emergence of the concept of "Russian" in the Constitution of the Russian Federation]. Federal'noe agentstvo novostei. Available at: https://riafan.ru/1254956-eksperty-rasskazali-k-chemu-privedet-poyavlenie-ponyatiya-russkie-v-konstitucii-rf (accessed 28.09.2020).

22. Predsedatel' Soveta Ottsov Tuvy podderzhal prezidentskie popravki v Konstitutsiyu o yazykakh [The Chairman of the Council Fathers Tuva supported the presidential amendments to the Constitution on languages]. Tuva-onlain. Available at: https://www.tuvaonline. ru/2020/03/04/predsedatel-soveta-otcov-tuvy-podderzhal-prezidentskie-popravki-v-konstituciyu-o-yazykah.html (accessed 28.09.2020).

23. Rakhmatullin T. Komu na ruku "russkaya stat'ya" v Konstitutsii? [Who benefits from the "Russian article" in the Constitution?]. Real'noe vremya. Available at: https://realnoevremya.ru/articles/167691-komu-budet-na-ruku-russkaya-statya-konstitucii (accessed 28.09.2020).

24. Fedorova E. Shevchenko Maksim: "Esli russkii narod gosudarstvoobrazuyushchii, to tatary kakoi?" [Shevchenko Maxim: "If the Russian people are state-forming, what are the Tatars like?']. Moskovskii Komsomolets - Kazan. Available at: https://kazan.mk.ru/ politics/2020/03/04/maksim-shevchenko-esli-russkiy-narod-gosudarstvoobrazuyushhiy-to-tatary-kakoy.html (accessed 28.09.2020).

25. Kholmogorov E. S. Russkaya problema [The Russian Problem]. Russkii dom. 2014, no. 1. Available at: http://www.russdom. ru/node/7400 (accessed 28.09.2020). 